\title{
UMA ANÁLISE BIOÉTICA DA RELAÇÃO PACIENTE-MÉDICO À LUZ DO ARQUÉTIPO DA ALTERIDADE
}

\author{
A BIOETHICAL ANALYSIS OF THE PATIENT-MEDICAL RELATIONSHIP IN THE \\ LIGHT OF THE ALTERITY ARCHETYPE
}

Recebido: 05.03.2020

\begin{abstract}
Mônica Neves Aguiar
Doutora em Direito das Relações Sociais pela Pontifícia Universidade Católica de São Paulo. Coordenadora do Programa de Pós Graduação em Direito da Universidade Católica do Salvador. EMAIL: monicaaguiarpsi@gmail.com LATTES: http://lattes.cnpq.br/7536438369531146 ORCID: http://orcid.org/0000-0002-4555-423X
\end{abstract}

Aprovado: 25.02.2020

RESUMO: Este artigo se propõe a analisar a relação paciente-médico a partir de uma construção bioética embasada com a Teoria Simbólica de Carlos Amadeu Botelho Byngthon, a qual traz como pilares de um relação humanizada fatores como a compreensão, o diálogo e o acolhimento do paciente. A partir de uma construção histórica da bioética, o presente trabalho busca analisar as possíveis contribuições do Arquétipo da Alteridade para a efetivação de uma relação entre médicos e pacientes que seja construída democraticamente e capaz de promover a expressão mais profunda e verdadeira de cada um dos sujeitos, possibilitando um tratamento humanizado e digno ao paciente vulnerável. Assim, utilizando o raciocínio dedutivo e análise bibliográfica que inclui referencias multidisciplinares, a partir de uma construção arquetípica, é apresentada a alteridade como elemento central de uma releitura bioética da relação médico-paciente. Com isso, a pesquisa traz como principal resultado a releitura da relação paciente-médico, a qual historicamente suscita grandes debates no campo bioético, estabelecendo como referencial teórico a Psicologia Simbólica Junguiana na tentativa de estabelecer um embasamento voltado para uma relação de paridade que consiga incorporar os valores de cuidado decorrentes do arquétipo matriarcal não se esquivando da aplicação objetiva do conhecimento construído, caminhando, pois, para uma nova interpretação da ética aplicada que leve em consideração uma análise da postura médica à luz da alteridade.

PALAVRAS-CHAVE: Alteridade. Bioética. Relação paciente-médico.Teoria Arquetípica.

ABSTRACT: This article aims to analyze the patient-doctor relationship based on a bioethical
construction based on the Symbolic Theory of Carlos Amadeu Botelho Byngthon, which
brings as pillars of a humanized relationship factors such as understanding, dialogue and the
reception of the patient. Based on a historical construction of bioethics, the present work seeks
to analyze the possible contributions of the Alterity Archetype for the realization of a
relationship between doctors and patients that is democratically constructed and capable of
promoting the most profound and true expression of each of the subjects, enabling
humanized and dignified treatment for vulnerable patients. Thus, using deductive reasoning
and bibliographic analysis that includes multidisciplinary references, based on an archetypal
construction, alterity is presented as the central element of a bioethical reinterpretation of the
doctor-patient relationship. With this, the research brings as a main result the reinterpretation
of the patient-doctor relationship, which historically raises great debates in the bioethical 
field, establishing the Jungian Symbolic Psychology as a theoretical reference in an attempt to establish a foundation focused on a parity relationship that manages to incorporate the values of care resulting from the matriarchal archetype do not shy away from the objective application of constructed knowledge, thus moving towards a new interpretation of applied ethics that takes into account an analysis of medical posture in the light of Alterity.

KEYWORDS: Alterity. Bioethics. Archetypal Theory. Patient-doctor relationship.

SUMÁRIO: 1 Introdução 2 Breve análise histórica e conceitual da Bioética 3 A alteridade como arquétipo 4 Uma proposta de aplicação da Bioética "alterizada" na relação pacientemédico 5 Considerações finais 6 Notas de referência

\section{Introdução}

O presente trabalho busca analisar e questionar o a relação médico-paciente, aqui compreendida como relação paciente-médico, como um campo bioético que deve ser analisado à luz da bioética, incorporando como marco teórico a Teoria Simbólica Junguiana. Importa destacar que esta inversão de nomenclatura aqui adotada para demarcar a noção de uma necessária equalização entre sujeitos que polarizam a relação, o que perpassa a transição do paciente para o primeiro plano da relação, inclusive no signo linguístico, numa demonstração de reconhecimento da dignidade e autonomia do paciente.

Historicamente a relação médico-paciente foi muito discutida no âmbito da bioética pelos conflitos intrínsecos ao tratamento desigual conferido a partir de uma suposta superioridade técnica e intelectual em detrimento do respeito à autonomia e, inclusive, do necessário respeito aos direitos humanos e fundamentais dos pacientes, o que se traduziu a partir de experimentos e tratamentos muitas vezes impetuosos e sem a devida preocupação com a informação do sujeito com relação ao seu quadro clínico.

Assim, em resposta aos abusos históricos a bioética e a ética médica começaram a caminhar no sentido de obrigatoriedade da informação para o paciente, mas sem se preocupar efetivamente como a humanização e a autonomia do sujeito, a partir do que se convencionou chamar de medicina defensiva, no entanto, sem que este patamar atingisse de fato o que se pretende com a efetivação da bioética.

Essa gradativa evolução tem sido fundamentada a partir de diversos argumentos interdisciplinares que se incorporam as recentes pesquisas em bioética. Assim, o presente trabalho visa, de forma pioneira, utilizar a alteridade enquanto marco da teoria proposta por Byingthon, o qual analisa a relação a partir dos arquétipos matriarcal e patriarcal (inerentes ao sujeitos) os quais devem ser equalizados em prol do Outro, construindo assim um novo passo teórico em direção ao que se pretende no campo da humanização das relações construídas no campo bioético.

A tarefa inicial que se propõe é a de construir um breve panorama conceitual e histórico da bioética para a compreensão da relação médico-paciente como um âmbito no qual muitos conflitos suscitaram debates e protestos, muitas vezes por demonstrarem uma ausência de reconhecimento da vulnerabilidade do paciente.

Afigura-se necessário, assim, repensar o tratamento médico conferido ao paciente à luz do arquétipo da alteridade. Neste sentido, destaca-se uma abordagem da relação pacientemédico a partir de uma evolução histórica que caminha para a humanização, considerando o tratamento como instituto construído a partir do diálogo e da vontade do sujeito. 
Assim, o presente trabalho pretende analisar, à luz arquétipo da Teoria Simbólica Junguiana, proposta por Carlos Byingthon, se a alteridade pode se apresentar como paradigma adequado de relação, afastando-se de um viés hierarquizado entre os sujeitos.

A partir desta abordagem, será verificado se a relação do profissional de saúde com os pacientes pode ser exercitada a partir do que se extrai de contribuição da noção arquetípica de alteridade e quais seriam as alterações promovidas no modelo de cuidado com o outro e de compreensão da doença, a partir do equilíbrio entre os arquétipos patriarcal e matriarcal, necessários ao desenvolvendo uma relação simétrica fundamentada no diálogo, na pluralidade e na alteridade.

O artigo utiliza o raciocínio dedutivo para alcançar a conclusão de que a construção arquetípica pode se constituir como argumento de inovação na bioética em prol de um tratamento mais humanizado no âmbito paciente-médico. A pesquisa se constrói a partir de análise bibliográfica, que inclui referencias multidisciplinares, centrada na teoria de Carlos Byingthon, o qual apresentada a alteridade como elemento central de uma abordagem definida a partir dos arquétipos matriarcal e patriarcal, os quais colaboram do ponto de vista epistemológico para uma releitura bioética da relação médico-paciente.

\section{Breve Análise Histórica E Conceitual Da Bioética}

O termo bioética - bioethics - foi cunhado pelo oncologista norte-americano Van Rensselaer Potter em 1970, pelo que ficou conhecido como o "pai da bioética". No entanto, alguns autores lembram que esse título reflete uma pesquisa já preexistente, que lhe foi atribuída por conta da criação do neologismo, o qual Potter definiu como "ciência da sobrevivência". Para ele a bioética se constituiria numa ponte entre a ciência biológica e a ética que deveria conduzir o progresso da humanidade!.

Em 1971, mesmo ano da publicação do artigo de Potter, o termo bioética foi empregado pelo também americano Andre Hellers, que fundou em julho o Joseph and Rose Kennedy Institute for the Study of Human Reproductions e Bioethics, "assim introduzindo o termo bioética pela segunda vez e, surpreendentemente, tanto quanto foi possível determinar, ainda com caráter inédito" ${ }^{\prime i i}$.

O instituto teria por finalidade a criação da disciplina a partir da elaboração de um programa para o Centro de Bioética, vinculado à Faculdade de Medicina e de Filosofia, despertando posteriormente o interesse do Instituto Nacional de Saúde. A instituição fundada por Hellergers, após sua morte (1979) tomou o nome de Kennedy Institute os Ethics, sendo oficialmente anexado à Georgetown University iii.

Maria do Céu Patrão Neves se refere a essa concomitância no aparecimento do termo em locais distintos e desconexos como "dupla paternidade" do termo, a qual reflete a "bilocalização da bioética". O surgimento do termo se apresenta como "fruto da época" e das diversas peculiaridades que norteavam a conjuntura da épocaiv.

Uma aproximação entre os autores "pais" do termo se estabelece na medida em que ambos, ao empregarem o termo bioética, demonstravam a preocupação de analisar os progressos científico-tecnológicos da época a partir de uma apreciação ética necessária naquele momento, tendo em vista o escândalo provocado pelas notícias envolvendo pesquisas científicas e violações aos direitos dos pacientes.

Os três casos principais que chocaram a população americana, fundamentais para o desenvolvimento das pesquisas em bioética, os quais fomentaram a ideia de inafastabilidade entre os avanços médicos e a questão da ética, foram: a) em 1963, no Hospital Israelita de Doenças Crônicas, em Nova York, injetaram células cancerosas vivas em idosos doentes com o 
intuito de pesquisa; b) entre 1950 e 1970, no Hospital Estadual de Willowbrook, em Nova York, injetaram o vírus da hepatite em crianças com deficiência mental; c) em 1932, no Estado do Alabama, no que foi conhecido como o caso Tuskegee, 400 negros com sífilis foram recrutados para participarem de uma pesquisa de história natural da doença e foram deixados sem tratamento. Em 1972, a pesquisa foi interrompida após denúncia no The New York Times

O despertar da bioética costuma ser associado a estes eventos famosos "que causaram espanto e alarme, porque em nome do bem-estar e da ciência foram transgredidos princípios elementares de respeito à dignidade e à vida das pessoas" ${ }^{\prime \prime}$. A partir destes episódios, em 1974, o Congresso norte-americano constitui a Comissão Nacional para a proteção dos Seres Humanos em Pesquisas Biomédica e Comportamental, que organizou o Relatório Belmont, divulgado oficialmente em 1978, o qual refletia a preocupação com as questões clínicas ligadas às pesquisas com seres humanos, se estabeleceu como uma das obras que fomentou ainda mais as questões envolvendo a bioéticavii.

Nesse contexto de crise da ética normativa frente aos casos supracitados, que antecipavam uma falência de valores universais para regerem as condutas humanas e as experiências científicas, a bioética assumiu a tarefa de reconstruir os parâmetros para fundamentar as condutas médicas no respeito e na dignidade para com o outro e para com a comunidade viii.

Com o intuito de melhor compreender a nova "ciência" que surgia, foi criada a Enciclopédia de Bioética, importante obra que teve sua primeira edição lançada em 1978, cujo editor-chefe era Warren Thomas Reich, e trouxe a seguinte definição para o termo: "Bioética é o estudo sistemático da conduta humana na área das ciências da vida e a atenção à saúde, enquanto que esta conduta é examinada a luz dos princípios e valores morais".

Nova edição, revista e ampliada, sob responsabilidade do mesmo editor-chefe foi publicada quase vinte anos depois, em 1995, e contemplou novos valores e questões que foram incorporados ao estudo da bioética, apresentando esta incorporação, inclusive, no novo conceito que foi exposto na obra: "Pode-se defini-la como o estudo sistemático das dimensões morais incluído visão, decisão, conduta e normas morais - das ciências da vida e da saúde, utilizando uma variedade de metodologias éticas num contexto interdisciplinar".

Em 2004, outra versão é lançada, já numa perspectiva de uma ciência consolidada e reconhecida na área científica. A obra teve como editor-chefe Stephen Garrard Post, indicado pelo antigo editor. Trouxe uma série de inovações, incorporando mais de 100 novos verbetes ${ }^{i x}$, o que resultou das novas questões que surgiram, desde aquela época até a atualidade acerca da sobrevivência e da qualidade da vida humana, as quais continuam tendo como objeto de discussão o conflito existente entre as descobertas científicas e os valores que devem nortear sua aplicaçãox.

Assim, surge a primeira teoria de embasamento teórico da bioética, qual seja a Bioética Principialista. Trata-se de uma teoria que não apenas remonta às origens da bioética como exerce grande influência nos códigos de ética da diferentes profissões na área da saúde até hoje. Apesar de ser alvo de severas críticas, é inegável que a proposta de Beauchamp e Childress de uma teoria ética, baseada em princípios morais representa um grande passo para o estudo da bioética ${ }^{\mathrm{xi}}$.

Esta corrente se consolida a partir da publicação da obra Princípios da Ética Biomédica, em 1979, pelos autores Tom Beauchamp e James Childress, que sugeriram os princípios da autonomia, não maleficência, beneficência e justiça como embasamento de uma bioética consistente $e^{\mathrm{xii}}$.

A influência da corrente principialista - ou apenas principialismo - foi tão grande que a bioética é frequentemente associada a esta corrente americana. Muitos doutrinadores que se propõem a estudar a bioética o fazem a partir desta única perspectiva. Inclusive, algumas organizações científicas e diretrizes internacionais se apoderam destes princípios como verdade 
absoluta e os reproduzem em seus documentos como se fossem diretrizes da bioética e não de uma corrente específica ${ }^{\text {xiii. }}$.

Apesar de muito atrelada à obra e à pesquisa de Beuchamp e Childress, não se pode descartar que, numa perspectiva mais ampla, o termo principialismo designa todos os modelos que tem em comum as premissas principiológicas, partindo de enunciados teóricos que devem ser aplicados como forma de legitimar as práticas adotadas. Como exemplo de outras correntes que podem ser consideradas "principialistas" tem-se o modelo europeu apresentado na Declaração de Barcelona, o modelo contratualista de Robert Veach e o fundacional de Gert, Colver e Clouser ${ }^{\text {xiv }}$.

Numa evolução histórica, inclusive, diversos princípios tais como a vulnerabilidade passam a ser incorporados como sendo premissas da bioética, o que inclusive demonstra que trata-se de uma teoria em constante evolução e adaptação. Neste sentido, inclusive, estudos já incorporam a alteridade, inclusive, como princípio bioético, tal como, por exemplo, a corrente da Bioética Complexa.

Os dilemas bioéticos - notadamente aqueles oriundos da relação médico-paciente quando analisados a partir da bioética principialista, utilizando os quatro princípios basilares, tende a fomentar dilemas agudos pela ausência de hierarquia definida entre eles, bem como pela impossibilidade de se atender a todos eles em algumas situações mesmo quando precedidas de um delicado juízo prudencial ${ }^{\mathrm{x}}$.

Nesses mais de 40 anos de existência como ciência autônoma assim denominada a bioética evoluiu muito e adquiriu importante papel no âmbito científico e acadêmico. Passou ainda a atuar em diferentes campos, tendo destaque no âmbito do direito e da medicina, sobre os quais se debruça o presente trabalho. No entanto, não se pode cogitar que a bioética apenas se instituiu como ferramenta para analisar as pesquisas médicas e os saberes jurídicos. O domínio da bioética se estende além das responsabilidades médicas, incluindo "as responsabilidades políticas e culturais da coletividade e por isso vai além do âmbito da deontologia ${ }^{\text {xvi }}$ pura profissional e da ética médica"xvii.

A bioética apoia-se, assim, em dois componentes epistemológicos principais: um componente analítico, que investiga um conflito ou desvio ético envolvendo as Ciências da Vida; e um componente positivo, a partir do qual ações ou normas visando à resolução de conflitos são propostas e justificadas ${ }^{x v i i i}$. Importa destacar, justificando o objeto do presente trabalho, que muitos dos conflitos na seara bioética se incluem no contexto da relação entre paciente e médico, a qual muitas vezes se apresenta como hierarquizada e, por vezes, abusiva.

Trata-se de um campo do conhecimento baseado na ética prática e que trabalha numa perspectiva plural de acolhimento dos saberes de várias ciências, "além da filosofia, faz valer a sociologia, a antropologia, a psicologia e a comunicação, e incorpora estudos empíricos, quantitativos e qualitativos do agir moral em saúde" ${ }^{\prime \prime i x}$.

A bioética se constrói, neste sentido, como um campo do conhecimento baseado na ética prática e que trabalha numa perspectiva plural de acolhimento dos saberes de várias ciências, "além da filosofia, faz valer a sociologia, a antropologia, a psicologia e a comunicação, e incorpora estudos empíricos, quantitativos e qualitativos do agir moral em saúde" ${ }^{\prime x x}$.

A partir dessa pluralidade, é preciso que a bioética seja analisada sob as perspectivas interdisciplinares, a qual é proposta no presente trabalho com a interação com a Psicologia Simbólica Junguiana, a qual será proposta como fundamento de uma relação adequada entre médico e paciente.

\section{A Alteridade Como Arquétipo}


Carlos Byngthon, criador da Psicologia Simbólica Junguiana, apresenta uma nova perspectiva de formação da identidade a partir da elaboração simbólica coordenada pelos arquétipos. Essa identidade surge junto com a identidade do não-Ego, que será o Outro durante toda a vida. Assim, O Ego e o Outro nascem simultaneamente e são sempre o centro da identidade e da consciência, o que é exemplificado a partir da construção de gênero na qual o sujeito se descobre homem ao mesmo tempo em que percebe que não se enquadra no gênero feminino ${ }^{x \times i}$.

Para explicar a alteridade como arquétipo, necessário lançar mão dos arquétipos matriarcal e patriarcal. Enquanto que o primeiro estaria ligado à sensualidade, à fertilidade, ao cuidado e ao prazer, o arquétipo patriarcal foi elaborado a partir da lógica da hierarquização, da ordem, da eficiência e do objetivismo, tendo, inclusive, como sombra um componente genocidaxxii. Importante destacar que estão "ambos presentes na personalidade do homem e da mulher e em todas as culturas em combinações variáveis" "xiii. Sendo assim, não há que se falar em características femininas e masculinas, mas nos arquétipos matriarcal e patriarcal que se filiam às características centrais de prazer e hierarquização respectivamente.

$\mathrm{O}$ arquétipo patriarcal está presente "em sistemas hierarquizantes, (...) que estabelecem distinções para baixo, admitindo, pela mesma lógica, uma diferenciação para cima. Todo universo social, então, acaba pagando o preço da sua extremada desigualdade, colocando tudo em gradações" ${ }^{\prime \prime x i v}$.

Uma consequência possível da polarização do Arquétipo Patriarcal é a promoção de uma espécie de contra-cultura em variadas manifestações de rebeldia e de extrema independência pessoal, destacando-se a liberação do Arquétipo Matriarcal reprimido ${ }^{x \times v}$. Tal consequência pode ser verificada historicamente como o Festival de Woodstock que representou uma verdadeira extravasão do arquétipo matriarcal.

Conforme foi destacado por Byington, a necessidade de dominação e de autoridade inerentes ao arquétipo patriarcal, poderia se manifestar, em sua expressão de sombra como tendência suicida, homicida ou genocida, sendo esta última a que melhor reflete a noção de hierarquização e a necessidade de aniquilação da cultura desigual, a qual não se estabelece, a princípio, como aniquilzação física, mas fica evidente na noção de intolerância e colonização que se estabelece com as culturas diversas. Em algumas situações, como ocorreu na Alemanha, esta expressão suicida arrastou não somente Hitler, mas toda a sociedade para a prática da (literal) aniquilação do diferente ${ }^{x x v i}$.

A intolerância pode ser vista como o antônimo da compaixão, a qual se estabelece como base da Alteridade ${ }^{x x v i}$. Reconhecer e respeitar o diferente deveria fazer parte do cotidiano como comportamento natural. No entanto, a não aceitação do outro - com suas diferenças e vicissitudes - tem levado pessoas a comportamentos de intolerância, atingindo o outro no seu aspecto mais íntimoxxviii, a partir de uma posição patriarcal que exclui os grupos daqueles tidos como inferiores.

Exemplo dessa posição polarizada pode ser observada na dominação do continente africano, que contém grupos reunidos aleatoriamente e que hoje travam verdadeiros massacres inter-étnicos em decorrência de não se ter observado as identidades ali presentes ${ }^{x x i x}$. Para além da dinâmica simbiótica do matriarcal, que não diferencia o eu do outro, a lógica dominante do patriarcal, que hierarquiza o outro, surge um terceiro modelo de relação baseada no arquétipo da alteridade.

Para o autor, é a "posição dialética do arquétipo da alteridade, propiciadora do relacionamento simétrico entre Ego e o Outro, com direitos iguais, cada um incentivado democraticamente a expressar o mais profundo e verdadeiro de si mesmo" ${ }^{\prime \prime x x}$.

"O arquétipo da alteridade é, certamente, a maior contribuição da psicologia simbólica junguiana. Não somente por ser 'capaz de dar a todas as polaridades direitos iguais de expressão', 
mas também porque (...) age na consciência" ${ }^{\prime x x i}$. Trata-se, pois, de uma lógica baseada na sincronicidade, que "coordena o processo de elaboração de maneira dialética e sistêmica sempre em função da totalidade ${ }^{\text {xxxii }}$.

Tendo suas opiniões e práticas - decorrentes da cultura - ceifadas, julgadas, estigmatizadas e reprimidas sem que haja consenso, sem que haja diálogo, estar-se-á diante de uma postura hierarquizante, reflexo do arquétipo patriarcal, o que deve ser superado em razão da necessidade de concretização do arquétipo da alteridade. Ou seja, a solução para os problemas que incluem o estranhamento moral entre os sujeitos não está nem na intervenção forçada, nem no relativismo indiferente, sendo necessário um diálogo entre os indivíduos, com a função de construir uma relação pautada na experiência da alteridade.

Até mesmo porque, pensar pelo princípio da diferença é se afirmar enquanto diferente. A partir da representação, o princípio da diferença acaba sendo mediado pelo idêntico, pelo semelhante, pelo análogo. Torna-se necessário, pois, introduzir a diferença do pensamento; reconhecer as multiplicidades como transformadoras de ideia para compor a diferença na afirmação (e na negação); e, finalmente, tomar cuidado para não compreender o diverso como matéria do conceito idêntico, restaurando, assim, a diferença individuante ${ }^{x x x i i i}$.

Neste sentido, o símbolo só ganha destaque a partir da interpretação humana, não possuindo um único significado em si mesmo, o que Carlos Byigthon exemplifica através da metáfora do vírus que pode ensejar, ao mesmo tampo, a vacina e a doença. Isto porque, a elaboração simbólica é o melhor método para o símbolo revelar a sua própria interpretação, que inclui, até mesmo, o fato de ele estar ou não fixado, pois, os símbolos trazem sua própria interpretação nos significados que abrigam e na maneira como reagem à elaboraçãoxxxiv. Considerando que no âmbito da psicologia, esse caráter negativo do arquétipo se manifestaria na sombra, importa destacar a lição de Maria Helena Guerra:

Como todos os arquétipos, também o arquétipo da alteridade pode se expressar na luz ou na sombra. Se sob a perspectiva saudável este arquétipo considera e respeita o outro - no ensinamento cristão ele se traduz como amar o próximo como a ti mesmo -, em sua dimensão defensiva o outro é enganado, desrespeitado. Assim, a sombra deste arquétipo é vista principalmente na mentira, na demagogia, na corrupção, isto é, naquelas circunstâncias em que, por um lado, se sabe o que é o "correto" a ser dito, mas de outro, sabe-se que serão apenas palavras ${ }^{x \times x}$.

A análise acerca da não incorporação real do respeito ao outro a partir da ideia de demagogia é bastante providencial quando consideramos a ideia de uma informação supostamente em respeito ao paciente, mas que traduz em verdade uma preocupação egoísta da não punição, o que vem sendo estudado pela bioética como Medicina Defensiva, a qual corresponde a informação conferida ao paciente apenas como uma forma do médico se defender de demandas motivadas pela ausência do consentimento informado, o qual não apenas se estabelece como uma obrigação a partir dos códigos de ética, como também se incorpora como princípio bioético da Declaração Universal sobre Bioética e Direitos Humanos.

Sendo assim, será analisada possibilidade de pensar a bioética à luz do Paradigma da Alteridade, visando assim alcançar uma aplicação da Ética Prática que esteja mais atenta ao outro, nem estabelecendo relações a partir do patriarcal, as quais seriam hierarquizadas e distantes, nem a partir de um padrão voltado ao matriarcal, o qual se excessivamente aplicado conduziria a um paternalismo "disfarçado" de cuidado. 
O título do presente tópico menciona uma proposta Bioética que compreende a Alteridade de Byigthon como um dos pilares de construção e aplicação. Dito isso importa destacar que não se trata ainda de uma corrente bioética, mas sim de uma aplicação ética construída a partir da noção de diálogo com o diferente, o qual deve ser aplicado indistintamente em todas as relações humanas, mas especificamente merece destaque no presente artigo a relação paciente-médico.

A proposta de inversão da clássica nomenclatura médico-paciente é uma proposta de Alessandro Timbó, o qual compreende que a nomenclatura relação paciente-médicoseria mais adequada por sugerir que as condições socioculturais subjacentes do paciente sejam prioritariamente levadas em consideração quando da análise relacional e na tomada de decisão médica. Neste sentido:

Na esteira da atual doutrina bioética, a nomenclatura paciente-médico ainda aponta no sentido de tornar extremamente residuais e casuísticas as situações que justifiquem intervenções paternalistas fortes, que revelam um desrespeito para com os agentes autônomos e não os tratam como moralmente aptos, mas como algo menos que determinadores independentes de seu próprio bem ${ }^{\text {xxvi }}$.

Isto porque, a Bioética, Biodireito ou Direito Médico tem se incumbido de diversos dilemas éticos envolvendo a vida, no entanto muitos deles perpasam essa relação que foi historicamente constuída a partir de uma dominção do saber médico sobre a autonomia do outro, mas que hoje tem cedido lugar a um paradigma cada vez mais de centralidade no paciente, o que inclusive se traduz na nomenclatura aqui utilizada.

"A substituição do modelo virtuoso de inspiração hipocrática pela ética contratual que passou a vigorar na pós-modernidade ensejou como efeito secundário um progressivo distanciamento entre médico e paciente" ${ }^{\prime x x x v i i}$. As relações que outrora eram construídas a partir de uma relação duradoura com um médico que identificava a enfermidade, observava atentamente a sua evolução e atestava o seu desfecho com a cura, foi substituída por um modelo em que as consultas são rápidas e efêmeras, refletindo na relação a ausência de interesse, talvez até de ambas as partes, de construir uma ligação mais aprofundada entre os sujeitos.

Neste sentido, as transformações promovidas pela bioética "generan transformaciones éticas y políticas, debido a que sientan las bases a otras formas de hacer, de pensar, de sentir, de conocer y de enunciar los mundos y las relaciones e interconexiones que en ellos tienen lugar" "xxxviii. No que se refere as relações abordadas na presente pesquisa é urgente e necessário repensar a paridade da relação como uma efetivação necessária dos direitos humanos, incluindo autonomia, saúde e integridade.

Para José Roberto Mainetti, as transformações na medicina incluiriam três eixos principais: A transformação técnico-científica; a transformação social da relação médico-paciente, centrando este segundo como protagonista das decisões; a transformação política da saúde, tornando-a um bem social de economia expansiva no mundo atual ${ }^{\mathrm{xxix}}$.

O movimento de humanização no âmbito médico, o qual será explorado no presente capítulo, se apresenta como um dos desdobramentos das transformações, apresentando-se como cenário no qual o sujeito não mais se apresenta como objeto. Assim, foi possível o afastamento de processo de coisificação, mas não foi suficiente para uma mudança de paradigma com relação a ética e a dignificação do sujeito na relação médico-paciente.

Tem-se repetido que o paradigma da relação médico-paciente mudou radicalmente, do modelo paternalista para o modelo de cuidado centrado no doente - e não sua autonomia -, com quem se partilha a informação e a responsabilidade da decisão ${ }^{\times l}$. Tal compreensão é fundamental para analisar a construção de um modelo de atenção ideal no de atenção e cuidado ao paciente. 
Tal compreensão foi possível, em larga medida, pela obrigatoriedade da informação no âmbito clínico.

Neste sentido, inclusive, na tentativa de estabelecer uma relação entre autonomia e informação no âmbito da relação paciente-médico, Knorst (et.al.) destacam que a percepção sobre a atuação do médico no encontro clínico também vem modificando na atualidade, passando a ter uma abordagem holística na qual consideram como objeto de atenção não apenas as doenças do paciente mas também as necessidades de informação do paciente e até mesmo a uma empatia, muitas vezes necessária, para um bom andamento do diálogo ${ }^{\text {xi }}$.

A relação médico-paciente ideal deve ser compreendida como um acordo de interesses, na qual uma pessoa com demanda sanitária busca, voluntariamente, um profissional que possa

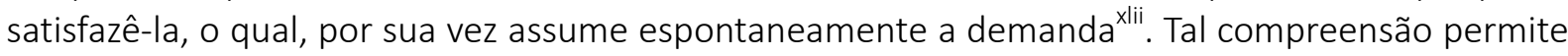
a criação de um plano terapêutico que, decorrendo do respeito mútuo, possa concatenar o saber médico sem descartar o saber e a autonomia do paciente.

A alteridade reforça e reconhece a dimensão do outro ser tratado como tal. Como diferente em seu modo de viver e ser no mundo, sem juízos de valor ou hierarquias, o que permite o respeito a sua singularidade e sua idiossincrasia. O encontro passa a ter uma perspectiva dialógica, sem a ânsia do convencimento ou da imposição. Só a partir da alteridade e o estranhamento causado a partir do encontro, é que o outro passa a ter existência.

A maior dificuldade para se conseguir tal feito enquanto sociedade, é conseguir se livrar de um entendimento proselitista perante os grupos sociais, ou seja, temos a tendência a querer homogeneizar as diferenças a todo custo, pois só conseguimos reconhecer aquilo que nos é igual. A diferença sempre terá um caráter negativo, o diferente só será bom, a partir do momento em que ele se transformar no modelo idêntico ao que Ihe é imposto." xliii

"Quando o profissional da saúde pretende relacionar-se com o outro como se relaciona com as coisas, dá-se conta que não compreende outrem, nem o domina como é capaz de fazer com as patologias presentes nos livros de fisiopatologia"xliv. Tal incapacidade de apreensão protesta pelo desenvolvimento de uma estratégia que leve em conta o encontro com o outro.

A racionalidade terapêutica invariavelmente ocupa seu espaço de ordenamento e fragmentação, muitas vezes polarizada no arquétipo patriarcal, despersonalizando, assim, as ações do cuidado. Esse tipo de relação favorece a despersonalização do ser humano, o que, por conseguinte, põe em risco a manutenção de sua dignidade ${ }^{x \mid v}$.

Desse modo, humanizar os serviços de saúde implica em transformar o próprio modo como se concebe o paciente, não o considerando como sujeito incapaz de exercitar a autonomia, nem tampouco como necessitado de atos de caridade. Para modificar o paradigma atual é necessário que os profissionais envolvidos no processo tenham, além da qualificação técnica, disponibilidade para cuidar.

Na constante missão de relacionar-se, o Outro espera do Eu reconhecimento que dignifica e aplaca as misérias materiais e morais decorrentes dos sofrimentos sociais. A preocupação com o próximo, integrante de um plano terapêutico voltado à diminuição do sofrimento do paciente se concretiza, muitas vezes, sob a forma de relação embasada na amorosidade, que promove um passo na direção do bem e da justiça social, consolidando os valores e a estabilidade da democracia ao propor uma perspectiva de aprimoramento pessoal de cada cidadão a partir da educação consciente e transformadora ${ }^{\text {xlvi }}$.

Neste sentido, afasta-se das deliberações paternalistas, na medida em que não compreende que o detentor do saber deve tomar decisões sem considerar as opiniões dos 
"outros", supondo que assim está agindo em benefício deles. Esta perspectiva de cuidado e atenção ao sujeito se afasta do tradicional modelo onde existe uma valorização do saber técnico desfavorecendo outros saberes, de ordem emocional e social| ${ }^{\text {kvii }}$.

A construção de uma relação que ultrapasse a distância entre os polos representados pelos médicos e pacientes compreenderia o que Maria do Céu Patrão Neves denomina "alterlogia", a qual pressupõe a superação das dicotomias sem a supressão da diferença, porque só na pluralidade se pode preservar cada um e complementar ambos. Assim poderá se conceber uma visão inclusiva da humanidade e integradora das pessoas. Para isso, deve-se compreender que nunca nada nem ninguém deve ser indiferente ao Eu, compreendendo que sempre tudo e todos the dizem respeito, o que não admite a substituição pelo Outro, tampouco permite a indiferença em relação ao outro xlviii.

A constituição de um plano terapêutico deve ser construída com base em uma relação de amorosidade com o paciente vulnerável. Essa relação não se constitui como mera utopia, mas como o resultado de uma formação médica que de compreenda a enfermidade a partir da construção de um modelo de tratamento que atenda o sujeito à luz dos seus interesses e vicissitudes.

A alteridade seria, pois, pilar deste novo modelo de relação médico-paciente, a qual valoriza e dignifica o outro, contribuindo para a simetria das relações, as quais, quando embasadas pelo individualismo egocêntrico, não raramente se tornam autoritários, prepotentes e mesmo agressivas. O modelo centrado na alteridade como premissa, deve prezar para a implementação de novas estratégias de cuidados construídas em conjunto por paciente e médico, a qual valoriza os sujeitos e os coloca em relação de paridade e sincronicidade.

\section{Considerações Finais}

Apesar da discussão envolvendo a relação médico-paciente ser recorrente no âmbito da bioética, cada vez mais novos argumentos e teorias são incorporadas na tentativa de estabelecer um tratamento digno ao paciente, o que se constrói a partir de novas teorias ou de novos argumentos. Assim, a psicologia e os arquétipos característicos da corrente simbólica jungiana podem se apresentar como um argumento que transcende os dispositivos objetivos dos códigos de ética médica e de regulamentação específica do direito médico para adentrar em um campo ainda pouco explorado acerca da postura dos profissionais de saúde que é a sua psiquê, a qual se traduz a partir de um comportamento por vezes distanciador regido pelo patriarcal, o que deve ser paulatinamente substituído por um tratamento mais "alterizado" fundado numa relação entre os sujeitos.

Para a construção de uma ética prática que incorpore os argumentos trazidos no texto, inicialmente a bioética foi apresentada como uma disciplina que apresentou em suas origens uma preocupação com a vida numa dimensão ambiental, proposta por Potter, e também a partir da centralidade nos dilemas individuais, notadamente aqueles relacionados a ética biomédica, a qual exerceu grande influência nos códigos de ética de diferentes profissões na área da saúde até hoje.

Para uma melhor compreensão da relação paciente-médico, se fez importante o conhecimento acerca construção da individualidade de cada sujeito, a qual foi apresentada a partir dos arquétipos matriarcal e patriarcal, os quais balizaram a construção de Carlos Byngthon da alteridade como arquétipo. Importa destacar que a história da bioética enquanto disciplina autônoma já remonta uma série de abusos. E a partir da sua apropriação enquanto ramo com epistemologia própria a interdisciplinaridade passa a ser uma característica que permite o florescimento de teses com argumentação muito além do campo do Direito, da Medicina, da Biologia ou de qualquer outro campo específico. A compreensão desse fenômeno da 
interdisciplinaridade pode colaborar no sentido de estabelecer novas premissas à luz da corrente teórica abordada, a qual se ramifica a partir do campo da Psicologia.

$\mathrm{O}$ argumento da alteridade passa a ser fundamento, pois, na construção de uma realidade de enfretamento bioético de problemas inerentes a relação paciente-médico, embasando a proposição de uma tentativa de superação da dicotomia prejudicial nesse âmbito, o que muitas vezes ensejou a inferiorizarão e exclusão da vontade do paciente na tomada de decisão clínica.

Assim, acredita-se que a relação do profissional de saúde com os pacientes deve ser exercitada a partir do que se extrai de contribuição da noção arquetípica de alteridade em virtude do seu compromisso de cuidado com o outro, devendo não apenas proporcionar a cura da doença, de forma hierarquizada e patriarcal, mas desenvolvendo uma relação simétrica fundamentada no diálogo, na compreensão e na alteridade.

A resposta está, pois, em analisar a influência da materialização de um saber soberano nas relações entre paciente e médico, constituindo um modelo de práticas discursivas regidas por dois elementos principais: a informação e a alteridade. Isto porque, uma abordagem terapêutica eficaz só será alcançada, pois, a partir da compreensão do indivíduo e do seu empoderamento na relação com o profissional de saúde, incluindo a troca de experiências entre ambos, a valorização do saber criado pelo indivíduo para lidar com as questões inerentes ao seu corpo e ao seu tratamento e a análise dos problemas por ele apresentados a partir da construção voltada para a aplicação de um conhecimento de caráter patriarcal aliada a uma abordagem de cuidado matriarcal que valoriza e dignifica o outro, contribuindo para a simetria das relações e para o sucesso da abordagem terapêutica.

\section{Notas de Referência}

'PESSINI, Leocir; BARCHIFONTAINE, Christian de Paul de. Problemas atuais da bioética. 10. ed. São Paulo: Centro Universitário São Camilo, 2012, p. 35-37.

ii NEVES, Maria do Céu Patrão; OSSWALD, Walter. Bioética Simples. Lisboa: Verbo, 2008, p. 16.

iii RODRIGUES, Maria Rafaela Junqueira Bruno. Biodireito: Alimentos transgênicos. São Paulo: Lemos e Cruz, 2002, p. 48.

iv NEVES, Maria do Céu Patrão. Bioética e bioéticas. In: NEVES, Maria do Céu Patrão; LIMA, Manuela (Orgs.) Bioética ou bioéticas na evolução das sociedades. Coimbra/São Paulo: Editora Gráfica de Coimbra/Centro Universitário São Camilo, 2005, p. 288.

$\checkmark$ PROJETO GHENTE. Bioética: Histórico. 2014. Disponível em: http://www.ghente.org/bioetica/historico.htm. Acesso em: 23 jul. 2014.

vi STEPKE, Fernando Lolas. Bioética e Medicina: aspectos de uma nova relação. Tradução Gilmar Saint Clair Ribeiro. São Paulo: Edições Loyola, 2006, p. 159.

vii SOARES, André Marcelo; PIÑEIRO, Walter Esteves. Bioética e biodireito: Uma introdução. 2 ed. São Paulo; Edições Loyola, 2006, p. 31.

viii ANJOS, Márcio Fabri dos. Introdução. In: ANJOS, Márcio Fabri dos; SIQUEIRA, José Eduardo de (Orgs.). Bioética no Brasil: tendências e perspectivas. São Paulo: Idéias e Letras; Sociedade Brasileira de Bioética, 2007, p.17.

${ }^{i x}$ PESSINI, Leocir; BARCHIFONTAINE, Christian de Paul de. Problemas atuais da bioética. 10. ed. São Paulo: Centro Universitário São Camilo, 2012, p. 43.

${ }^{x}$ MINAHIM, Maria Auxiliadora. A vida pode morrer? Reflexões sobre a tutela penal da vida em face da revolução biotecnológica. In: BARBOZA, Heloisa Helena; MEIRELLES, Jussara Maria Leal de; BARRETTO, Vicente de Paulo (Orgs.) Novos Temas de Biodireito e Bioética. Rio de Janeiro: Renovar, 2003, p. 99. 
${ }^{x i}$ DEJEANNE, Solange. Os fundamentos da bioética e a teoria principialista. In: Thaumazein: Revista on-line de filosofia, Santa Maria-RS, ano IV, n.7, p. 32-45, jul. 2011. Disponível em: http://sites.unifra.br/Portals/1/ARTIGOS/nro_06/SOLANGE.pdf. Acesso em: 10 out. 2014, p. 34. xii DINIZ, Débora e GUILHEM, Dirce. O que é Bioética? São Paulo: Brasiliense, 2012, p. 38.

xiii DURAND, Guy. Introdução geral à Bioética: história, conceitos e instrumentos. 4 ed. São Paulo: Centro Universitário São Camilo: Loyola, 2012, p. 53.

xiv NEVES, Maria do Céu Patrão; OSSWALD, Walter. Bioética Simples. Lisboa: Verbo, 2008, p. 103.

${ }^{x v}$ ZUBEN, Newton Aquiles Von. Vulnerabilidadee Decisão: tensão no pacto médico. In:

BARCHIFONTAINE, Christian de Paul de; ZOBOLI, Elma (Orgs.) Bioética, vulnerabilidade e saúde. São Paulo: Centro Universitário São Camilo, 2007, p. 69.

xvi Deontologia é uma filosofia que faz parte da filosofia moral contemporânea, que significa ciência do dever e da obrigação. Deontologia é um tratado dos deveres e da moral. É uma teoria sobre as escolhas dos indivíduos, o que é moralmente necessário e serve para nortear o que realmente deve ser feito.

xvii BELLINO, Francesco. Fundamentos da bioética: aspectos antropológicos, ontológicos e morais. Bauru: EDUSC, 1997, p. 47-48.

xviii NERY FILHO, Antônio; LORENZO, Cláudio; DIZ, Fátima. Usos e usuários de substâncias psicoativas: considerações bioéticas. In: BRASIL. Secretaria Nacional de Políticas sobre Drogas. Prevenção dos problemas relacionados ao uso de drogas: capacitação para o conselheiros e lideranças comunitárias. Brasília: SENAD; MJ, 2014, p. 130.

xix JUNGES, Jose Roque; ZOBOLI, Elma Lourdes Campos Pavone. Bioética e saúde coletiva: convergências epistemológicas. Revista de Ciência e saúde coletiva. Rio de Janeiro, v.17, n.4, 2012, p. 1051.

xx JUNGES, Jose Roque; ZOBOLI, Elma Lourdes Campos Pavone. Bioética e saúde coletiva: convergências epistemológicas. Revista de Ciência e saúde coletiva. Rio de Janeiro, v.17, n.4, 2012, p. 1051.

${ }^{x \times i}$ BYINGTON, Carlos Amadeu Botelho. Psicopatologia simbólica junguiana: um estudo do mal e da ameaça de autodestruição da nossa espécie. 2 ed. São Paulo: Edição do autor, 2017, p. 35.

xxii BYINGTON, Carlos Amadeu Botelho. Psicopatologia simbólica junguiana: um estudo do mal e da ameaça de autodestruição da nossa espécie. 2 ed. São Paulo: Edição do autor, 2017, p. 146 e 205. xxiii BYINGTON, Carlos Amadeu Botelho. Psicopatologia simbólica junguiana: um estudo do mal e da ameaça de autodestruição da nossa espécie. 2 ed. São Paulo: Edição do autor, 2017, p. 38.

xxiv DAMATTA, Roberto. Relativizando: Uma introdução a antropologia social. Rio de Janeiro: Rocco, 1987, p. 75.

xxv BYINGTON, Carlos Amadeu Botelho. Psicologia simbólica junguiana: a viagem de humanização do cosmos em busca da iluminação. São Paulo: Linear B, 2008, p. 282.

xxvi BYINGTON, Carlos Amadeu Botelho. Psiquiatria e política: a psicopatia Individual e coletiva no nacional socialismo: um Estudo da Psicologia Simbólica. Disponível em: http://www.carlosbyington.com.br/site/wp-

content/themes/drcarlosbyington/PDF/pt/psiquiatria_e_politica.pdf. Acesso em: 15 mar. 2018.

xxvii MAIA, Merlânio. Arte e alteridade. In: CLíMACO, Fernando (et al.). Alteridade: a diferença que soma. Belo Horizonte: INEDE, 2005, p. 139.

xxviii RICETTI, Simone Maria. Bioética e arte: encontro da subjetividade e reconhecimento do outro. In: RENK, Valquíria; RAULI, Patrícia Maria Forte. Bioética e Educação. Curitiba: CRV, 2016, p. 150.

xxix BYINGTON, Carlos Amadeu Botelho. Psicologia simbólica Junguiana: A viagem de humanização do cosmos em busca da iluminação2 ed. São Paulo: 2015, p. 192.

${ }^{x x x}$ Idem., 2017, p. 51. 
xxi AGUIAR, Mônica. O arquétipo da alteridade como paradigma necessário ao afastamento da alienação parental. In: Direito de família. CONPEDI/UFPB; Coordenadores: Carolina Valença Ferraz, José Sebastião de Oliveira, Luciana Costa Poli. - Florianópolis: CONPEDI, 2014, p. 247.

xxxii BYINGTON, Carlos Amadeu Botelho. Psicologia simbólica Junguiana: a viagem de humanização do cosmos em busca da iluminação. 2 ed. São Paulo: 2015, p. 2015.

xxxiii SILVA, Nilza. Subjetividade. In: STREY, Marlene Neves (et. al.) Psicologia social contemporânea: livro-texto. Petrópolis: Vozes, 2013, p. 172.

xxxivBYIGTHON, Carlos Amadeu Botelho. Psicopatologia Simbólico-Arquetípica. Disponível em: http://www.carlosbyington.com.br/site/wp-

content/themes/drcarlosbyington/PDF/pt/psicopatologia_\%20simbolico_arquetipica.pdf Acesso em: 07 abr. 2018.

xxxv GUERRA, Maria Helena Mandacaru. O arquétipo da alteridade em época de big data. Uma perspectiva da Psicologia Simbólica Junguiana. In: Revista da Sociedade Brasileira de Psicologia Analitica, 2ㅇs. sem. 2019, v.37-2, p. 17.

xxxvi TIMBÓ, Alessandro Timbó; SILVA, Mônica Neves Aguiar da. A relação paciente-médico: por uma nomenclatura bioética. In: Revista Direito e Justiça: Reflexões Sociojurídicas Santo Ângelo, v. 19, n. 35, set./dez. 2019, p. 86.

xxxvii SIQUEIRA, José Eduardo. Médico e paciente: amigos ou estranhos morais? In: PESSINI, Leo; BERTACHINI, Luciana; BARCHIFONTAINE, Chistian P. de. (orgs.) Bioética, cuidado e humanização. v. II. Sobre o cuidado respeitoso. São Paulo: Centro Universitário São Camilo: Edições Loyola: IBCC Centro de Estudos, 2013, p. 344.

xxxviii TOYA, Piedad González; FAGUNDES, Lucas Machado. Sentipensando en camino a un buen vivir: fundamentos otros a los derechos humanos desde la terapia del campo punto cero. In:

Revista Brasileira de Direito Animal, e-issn: 2317-4552, Salvador, volume 14, número 02, p. 7-29, Mai-Ago 2019, p. 08.

xxxix MAINETTI, José Alberto. O complexo bioético: Pigmaleão, Narciso e Knock. In: BARCHIFONTAINE, Christian de Paul de; PESSINI Leo (Orgs.). Bioética clínica e pluralismo. São Paulo: Centro Universitário São Camilo; Loyola; 2013, p. 293.

${ }^{x l}$ OSSWALD, Walter. Limites do consentimento informado. In: ASCENÇÃO, José de Oliveira (org.).

Estudos de Direito da Bioética, v. III. Coimbra: Almedina, 2009, p. 151.

xli KNORST, Gabriel Rocha; JESUS, Victor; MENEZES JR., Antônio. A relação com o médico na era do paciente expert: uma análise epistemológica. In: Revista Interface: comunicação, saúde, educação. v. 23, 2019, p. 05.

xlii DRUMOND, Joé Geraldo de Freitas. Bioética clínica e direito médico. In: BARCHIFONTAINE, Christian de Paul de; PESSINI Leo (Orgs.). Bioética clínica e pluralismo. São Paulo: Centro Universitário São Camilo; Loyola; 2013, p. 354.

xliii DÓBIES, Daniel Vannucci; BESSA, Victor Buratto Alves; FRANCISCHINI, Carina Fontana; SILVA, Matheus José da; SANTOS, Rosana Lourenço dos. Alteridade e convívio num CAPSad de Campinas/SP: estratégias e discussões. Trabalho apresentado no 60 Congresso internacional ABRAMD - Drogas e Autonomia: Ciência, Diversidade, Política e Cuidados. Grupo de Trabalho: CAPS ad: multiplicidade e trabalho vivo. Disponível em: <http://www.congressointernacional2017.abramd.org/arquivo/downloadpublic?q=YToyOntzOjY6I nBhcmFtcyl7czozNDoiYToxOntzOjEwOiJJRF9BUIFVSVZPIjtzOjM6ljYxNil7fSI7czoxOiJoljtzOjMyOiJkM GEzMzI1ZTE2OGZkZGM2ZmlyOWExMjgzNDM0ZTBhNCI7fQ\%3D\%3D>p. 11.

xliv ALMEIDA, Debóra Vieira; RIBEIRO JUNIOR, Nilo. Ética, alteridade e saúde: o cuidado como compaixão solidária. In: PESSINI, Leo; BERTACHINI, Luciana; BARCHIFONTAINE, Chistian P. de. (orgs.) Bioética, cuidado e humanização. v. II. Sobre o cuidado respeitoso. São Paulo: Centro Universitário São Camilo: Edições Loyola: IBCC Centro de Estudos, 2013, p. 242. 
xIv BETTINELLI, Luiz Antonio; PORTELLA, Marilene Rodrigues; ERDMANN, Alacoque Lorenzini; SANTINA, Janaína Rigo. Dignidade humana: cuidado à saúde e humanização. In: PESSINI, Leo; BERTACHINI, Luciana; BARCHIFONTAINE, Chistian P. de. (orgs.) Bioética, cuidado e humanização. v. II. Sobre o cuidado respeitoso. São Paulo: Centro Universitário São Camilo: Edições Loyola: IBCC Centro de Estudos, 2013, p. 355.

xlvi MOURA, Rafael Soares Duarte de. A hermenêutica filosófica da alteridade: análise fenomenológica da justiça fundada na ética do amor. Dissertação (Mestrado) - Universidade Federal de Minas Gerais, Faculdade de Direito. Belo Horizonte, 2012, p. 271.

xlvii BRAZ, Marlene. Bioética, proteção e diversidade moral: quem protege quem e contra o quê na ausência de um referencial moral comum? In: SCHRAMM, Fermin Roland; REGO, Sergio; BRAZ, Marlene; PALÁCIOS, Marisa. (Org.). Bioética, riscos e proteção. Rio de Janeiro: Editora UFRJ Editora Fiocruz, 2005, p. 58.

xlviii NEVES, Maria do Céu Patrão. Alteridade e Direitos Fundamentais: uma abordagem ética. Palestra proferida no I Congresso Internacional Direitos Fundamentais e Alteridade, Salvador, em 25 de maio de 2017. 